\title{
HISTOPATHOLOGIC AND IMMUNOHISTOCHEMICAL EVALUATION OF THE EFFECT OF GRAPE SEEDS EXTRACTS ON ALVEOLAR BONE AND PERIODONTAL LIGAMENT IN STREPTOZOTOCIN- INDUCED DIABETIC RATS
}

\author{
Shaimaa Mohammed Morsy*, Rasha Mohamed Taha** and Mona Saad Shata***
}

\begin{abstract}
Background: This study aims at clarifying if grape seed extracts (GSE) are candidates' therapeutic agents against the damaging effects of diabetes mellitus on the alveolar bone and periodontal ligaments.

Materials and methods: By randomly allocating 50 adult albino rats into five groups, each group included 10 rats as follows: Group I (negative control): served as controls; Group II: (positive control) diabetic rats receive no treatment; Group III: diabetic rats were treated with $50 \mathrm{mg} / \mathrm{kg}$ GSE for 6 weeks; Group IV: diabetic rats treated with $100 \mathrm{mg} / \mathrm{kg}$ GSE for 6 weeks; Group V: diabetic rats treated with $10 \mathrm{mg} / \mathrm{kg}$ gliclazides for 6 weeks. At the end of the experiment, extraction and preparation of rats jaws to examine their alveolar bone and periodontal ligaments histologically and immunohistochemically.
\end{abstract}

Results: Diabetic rats treated with GSE $100 \mathrm{mg} / \mathrm{kg}$ showed marked improvement of periodontal ligaments and alveolar bone with new bone formation compared to diabetic rats treated with GSE $50 \mathrm{mg} / \mathrm{kg}$ and Gliclazides $10 \mathrm{mg} / \mathrm{kg}$. Immunohistochemical analysis of $\mathrm{Bcl} 2$ in untreated diabetic rats has statistically significantly $(\mathrm{P} \leq 0.001)$ caused an increase in $\mathrm{Bcl} 2$ expression in comparison with diabetic rats that receive treatments. GSE $100 \mathrm{mg} / \mathrm{kg}$ has statistically significantly $(\mathrm{P} \leq 0.001)$ led the $\mathrm{Bcl} 2$ expression to decrease in comparison with GSE $50 \mathrm{mg} / \mathrm{kg}$ and diabetic rats treated with gliclazide.

Conclusion: GSE at dose $100 \mathrm{mg} / \mathrm{kg}$ improved the periodontal ligament and alveolar bone in diabetic rats it could be used as a supplement for treating diabetic patients with diabetes Mellitus.

KEYWORDS: Streptozotocin, Diabetes Mellitus, grape seeds extract, gliclazide, Bcl2

\footnotetext{
* Lecturer of Oral Medicine and Periodontology, Faculty of Dentistry, Suez Canal University.

**Associate Professor of Oral Biology, Faculty of Dentistry, Suez Canal University.

*** Lecturer of Oral Pathology, Faculty of Dentistry, Suez Canal University.
} 


\section{INTRODUCTION}

Described as chronic diseases, Diabetes mellitus and periodontal disease have an effect on a large number of populations all over the world. An important long-term complication related to diabetes mellitus is the changed bone metabolism. The loss of Alveolar bone is a key outcome of periodontitis and diabetes is one of the primary factors of risk for periodontal disease. ${ }^{(1)}$

Diabetes mellitus (DM) represents a metabolic disorder that is diagnosed by the increase in plasma glucose levels, it alters the inflammatory response, impairs tissue healing, disturbs the collagen production, and reduces the angiogenesis process. (2) DM has been considers to be the major risk factor in developing serious and gradual damage to periodontal tissue. Multiple biological variables are including microbial impacts, hyperglycemia, and immune cytokines have been attributed to the increased periodontal tissue damage in DM. ${ }^{(3)}$ The advanced glycation end-products (AGEs) are built up by the persistent increase in the blood glucose level, which In collagens, AGEs produce non-enzymatic cross-links thereby decreasing the flexibility of collagen matrix, which in turn leads to bone deformations. ${ }^{(4)}$

As bone density and diabetes have an intricate interplay, Diabetic patients are often led to osteopenia and extreme cases are associated with osteoporosis. In turn, this results in facilitating the loss of bone in these patients and leads them to an increased level of risk for negative outcomes in terms of bone health. ${ }^{(5)}$ Several additional factors are related to hyperglycemia and have an effect on bone micro-architecture in DM. As an example, glycosuria can proportionally can lead calcium excretion to increase in urine. In addition, the interaction between hyperglycemia and the parathyroid hormone (PTH) and vitamin D system has an effect on bone turnover in the population of patients living with DM. ${ }^{(6)}$
The key reason for the development of oxidative stress and the increase in producing reactive oxygen species (ROS) that enhance cellular oxidation is hyperglycemia. ${ }^{(7,89)} \mathrm{ROS}$ activates nuclear factorkappa B (NF- $x \mathrm{~B})$ is activated by ROS, following the increase in the expression of proinflammatory cytokine and chemokine. ${ }^{(10)}$ These mediators have a significant effect on bone by stimulating the osteoclast differentiation and activity. ${ }^{(11)}$ Moreover, ROS causes mitochondrial damage, which promotes the apoptotic pathway, starting with Bax pro-apoptotic proteins activation on the mitochondrial surface. ${ }^{(12)}$ Consequently, the increase in the ROS stimulates the expression of Bax and downregulation of $\mathrm{Bcl}-2$, which can inhibit the apoptotic cell death. ${ }^{(13,14)}$

Many active substances derived from plant-derived groups of different chemical compounds display a potent antioxidant activity, ${ }^{(15)}$ such as proanthocyanidins which is a major component of grape seeds extract. They have 20 times more powerful antioxidant activity than vitamin $\mathrm{C}$ and 50 times more effective than vitamin E. ${ }^{(16,17)}$ proanthocyanidins have a wide range of pharmacological and therapeutic effects, it has vasodilator, anticarcinogenic, anti-allergic, anti-inflammatory, antifungal, anti-arthritic, antibacterial, cardioprotective, immunostimulant, and antiviral properties which are remarkably significant. ${ }^{(18)}$

Grape seeds extracts (GSE) also efficiently reduce inflammatory cytokines' production including interleukin (IL)-17, tumor necrosis factor (TNF)- $\alpha$, nitrotyrosine, matrix metalloproteinase (MMP)-13, and osteoclastogenesis inhibition, ${ }^{(19,20)}$ and acts as a safeguard against alteration induced by stress in p53 production and the antiapoptotic protein ( $\mathrm{Bcl}-$ 2) in human oral epithelial. As a natural product, the GSE can be used in managing diabetes and its complications. ${ }^{(21)}$

GSE may strongly lead to the inhibition of osteoclast differentiation, the reduction of osteoclast activity, and the stimulation of bone formation through the positive action it has on osteoblast dif- 
ferentiation. As a result, it may be useful for treating the inflammation related to bone destruction. ${ }^{(22)}$ The anti-inflammatory effect of GSE is generated by the calibration of the delicate balance between pro-inflammatory and anti-inflammatory cytokines through the regulation of their release and gene expression. ${ }^{(23)}$ Nevertheless, the data on GSE effects on healthy and diseased periodontal tissues is limited. It was shown that GSE can protect against collagen breakdown, (24) and have a bacteriostatic influence on the anaerobes, which can result in a significant decrease in dental biofilm maturation. Consequently, it can be employed in preventing periodontal disease. ${ }^{(25)}$

This present study was designed for evaluating the influence of grape seeds extract on the alveolar bone and periodontal ligaments in diabetic rats.

\section{MATERIALS AND METHODS:}

This current study was approved by the Research Ethics Committee number 2021/385, Faculty of Dentistry, Suez Canal University, and all experiments were conducted according to the Guidelines for Experimental Animal Studies.

\section{Sample size calculation:}

By utilizing G*Power version 3.1.9.4, Faul et al., (2007), the sample size was estimated and the effect size was 0.65 using alpha $(\alpha)$ level of 0.05 and Beta $(\beta)$ level of 0.05 , i.e., power $=95 \%$; the minimum sample size (n) calculation was a total of 50 samples for 5 groups. ${ }^{(26)}$

\section{Animals and experimental model}

In total, 50 male albino rats (140-180 g) were used in the experiment. Animals were kept in groups, 3 rats in each cage during the experiment. They were provided with unlimited access to rat food and tap water. In addition, they were kept in a $12 \mathrm{~h}$ light/12 $\mathrm{h}$ dark cycle at the animal house of Suez Canal University and stored in an air-conditioned room at $21-23^{\circ} \mathrm{C}$ and $60-65 \%$ relative humidity.

\section{Grouping}

The rats were distributed to three groups (10 rats per each group) as follows:

Group I (-ve control): served as a negative control

Group II (Diabetic Group): a single intraperitoneal injection of streptozotocin (STZ) to given to rats. ${ }^{(27)}$

Group III: a single intraperitoneal injection of STZ was given to animals, the same as group II, then diabetic rats were treated with $50 \mathrm{mg} / \mathrm{kg}$ grape seed extract for 6 weeks. ${ }^{(28)}$

Group IV: a single intraperitoneal injection of STZ was given to animals, the same as group II, then using $100 \mathrm{mg} / \mathrm{kg}$ grape seed extract, the diabetic rats were treated for 6 weeks. ${ }^{(28)}$

Group V: a single intraperitoneal injection of STZ was given to animals, the same as group II, then using $10 \mathrm{mg} / \mathrm{kg}$ gliclazides, diabetic rats were treated for 6 weeks. ${ }^{(29)}$

\section{Induction of diabetes}

Before inducing diabetes, animals were kept fasting for 24 hours. Then, $60 \mathrm{mg} / \mathrm{kg}$ body weight of STZ, which were freshly dissolved in citrate buffer (0.1 M, pH 4.5), were intraperitoneally injected as a single dose to induce diabetes, while vehicle buffer was injected for negative control rats. Following STZ injection fasting blood glucose (FBG) level was examined at $72 \mathrm{~h}$ by obtaining blood sample from the tail vein of animals. On a glucose strip test in a glucometer (EasyGluco Blood Glucose Monitoring system, Infopia, Korea), a blood drop was placed and it was confirmed that rats are diabetic when the FBG level was above $250 \mathrm{mg} / \mathrm{dl}$. ${ }^{(27)}$

At the end of the experimental study, All rats were sacrificed using cervical dislocation. The samples of jaws of rats were collected for histological and immunohistochemical assessment. 


\section{Samples Preparation}

After the sacrifice, soft tissues are dissected in each specimen and the whole mandibles are removed and bisected. For bone decalcification, the specimens were assembled and immersed in $10 \%$ formalin, then after 24- 48 hours they were inserted in $10 \%$ EDTA (pH 7.4) and the solution was replaced every week for 3-5 weeks. The specimens were flushed with (phosphate buffered saline) PBS and then immersed in 70\%, 80\%, 96\% ethanol (90 minutes for each one), three absolute ethanol immersions (60 minutes each), two xylol immersions (90 minutes each) and two liquid paraffin immersions at $60^{\circ} \mathrm{C}$ (120 minutes each). Finally, mesiodistal sections ( $5 \mu \mathrm{m}$ thickness in width) at the molar area were sliced with microtomes from the blocks that were deparaffinized in an oven at $60^{\circ}$ overnight and in xylene for $1 \mathrm{~h}$ and then rehydrated to dye by using Masson's Trichrome, hematoxylin and eosin. Sections were examined for all groups in terms of alveolar bone resorption and degeneration, periodontal ligament, as well as new and mature bone formations.

\section{Procedure of immunohistochemical staining of BCL2 was carried as follows}

Sections of $5 \mu \mathrm{m}$ thickness were de-paraffinized in xylene, rehydrated by lowering alcohols, and stored in 3\% hydrogen peroxide phosphate buffers. Sections were placed in the oven for 20 minutes in $10 \%$ aqueous EDTA buffer, $\mathrm{pH}$ 7.4. Then, overnight, $50 \mu \mathrm{l}$ (1:50) rabbit polyclonal anti-Bcl2 antibodies were added incubated at $4^{\circ} \mathrm{C}$. Following incubation, an amount of $50 \mu \mathrm{l}$ biotinylated goat anti-rabbit immunoglobulin G secondary antibody (ThermoScientific, CA, USA) working solution was added. Then, it was incubated at $37^{\circ} \mathrm{C}$ for 30 minutes and was colored by utilizing diaminobenzidine. To evaluate the proliferation of positive immunoreactivity for $\mathrm{Bcl} 2$ in the periodontal ligaments and bone, an ordinary light microscope was used. Then, the optical density of Bcl 2 positive cells and the intensity of the immunostaining were assessed using the $\mathbf{J}$ Image analyzer computerized system.

\section{Statistical analysis}

In order to hold a comparison of the means of immunoreactivity of $\mathrm{Bcl} 2$ between different group, the ANOVA Test ( $\mathrm{F}$ test) was used for analyzing data. After one a way ANOVA (F test), a Post hoc test was carried out to identify whether there is any significant difference between the individual groups. $\mathrm{P}$-value was considered significant at $\mathrm{p}<0.05$.

\section{Hematoxylin and Eosin results}

Group I (Negative control group): by examining group I, the periodontal ligament composed of cells, fibers, blood vessels \& nerves were revealed. The collagen fibers which are the main components of the PDL were composed of the gingival group of fibers attached to the cervical part of the cementum and extended to the free and attached gingiva, where their fusion with the gingiva's lamina propria took place. The interdental or trans-septal group of fibers were extending from the cementum of one tooth to the adjacent tooth's cementum crossing above the alveolar bone's crest. The alveolo-dental group of fibers attached to the cementum from a side and to the alveolar bone on the other side and were subdivided into: the fibers of alveolar crest, horizontal, apical, and oblique inter-radicular fibers. Cells of the PDL were predominantly fibroblasts, progenitor cells and some of the defensive cells were seen. Interstitial spaces between the bundles of fibers were demonstrated having blood vessels and alveolar connective tissue. The alveolar bone appeared normal, consisted of the proper alveolar bone, and reinforced alveolar bone. The alveolar bone proper that forms sockets' inner walls and contains Zuckerkandl and Hirschfeld's canals openings was formed of bundle bone and lamellar bone. The fibers of Sharpey were inserted into the bundle bone, which is the alveolar bone prope's part that forms the innermost walls of the socket. Adjacent to it, the lamellar bone was found 
where the lamellae were arranged either parallel to each other or in the form of Haversian systems. The supporting alveolar bone is composed of spongiosa and cortical plates of compact bone. The alveolar bone showed normal turnover rate, as the number of the reversal lines were minimal. Besides, the PDL/ bone interface appeared to be smooth; no osteoclastic activity was observed. (Fig. 1)

Group II (Diabetic Group): examination of periodontal ligaments of rats injected with a single dose of STZ intraperitoneally for diabetes induction showed detachment and dissociation of the principle fibers, areas of vacuolization and dissolution of periodontal ligaments fibers and marked dilatation of blood vessels and areas of hemorrhage. The bone surface showed a lot of Howship' s lacuna and osteoclasts, widening of the marrow cavities $\&$ inflammatory cells infiltrate. Thinning of bone trabeculation and widening of Zuckerkandl and Hirschfeld canals also were noted. Hyercementosis was noted in some samples. (Fig. 2)

Group III: Diabetic animals treated with grape seeds $50 \mathrm{mg} / \mathrm{kg}$ for 6 weeks revealed poor progress in the bone and periodontal ligament status. Periodontal ligaments showed more organized periodontal ligaments focal areas of detachment, and fiber dissociation, dilatation of blood vessels and inflammatory cell infiltration. A lot of Howship' s lacuna and osteoclastic activity on the bone surfaces, widening of the marrow cavities, thinning of bone trabeculation, widening of Zuckerkandl and Hirschfeld canals and hypercemtosis was recorded. (Fig.3)

Group IV: animals treated with GSE in a $100 \mathrm{mg} / \mathrm{kg} /$ day dose for six weeks displayed partial improvement of periodontal ligaments, mostly in the arrangement and association of the fibers of PDL. The fibers mostly regained their arrangement and association together in bundles. Dilatation of the blood vessels was still observed, however in lesser degree. Alveolar bone showed new bone formation, a lot of reversal line minimal and Howships lacanue were recorded. (Fig. 4)

Group V : the animals treated with Gliclazide in a $10 \mathrm{mg} / \mathrm{kg} /$ day dose for 6 weeks showed improvement in periodontal ligaments orientation. Dissociation and detachment of the fibers from both tooth and bone sides were recorded. Dilatation of the blood vessels were observed, however in a lesser degree. Epithelial rest of malassezes were demonstrated in clusters or large proliferated clusters of cells. The bone-surface showed a lot of Howships lacunae and numbers of reversal lines. Zuckerkandl and Hirschfeld canals showed widening with blood vessels dilatation. Inflammatory cell infiltrations were recorded all over the periodontal ligaments. Cementum showed focal resorbed areas. (Fig 5)

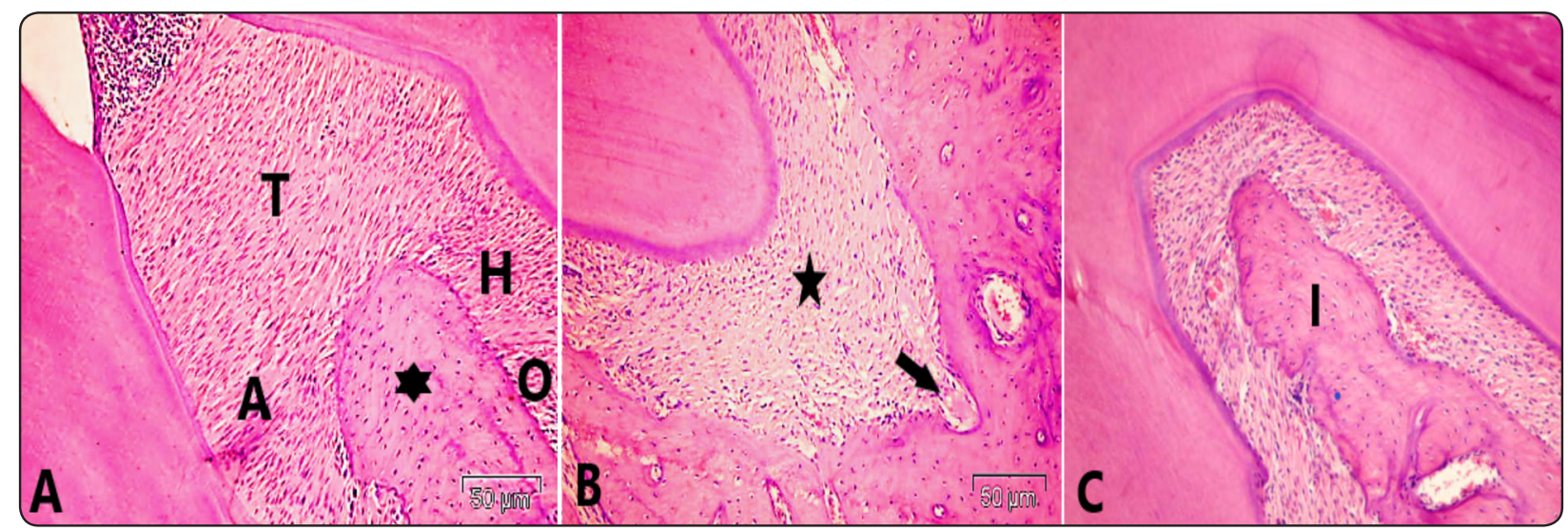

Fig. (1) A photomicrograph of group I showing (A) gingival, transseptal (T) alveolar crest (A), horizontal (H) and oblique (O) periodontal ligaments principle fibers Interseptal bone (star). (B) Apical principle fibers of periodontal ligaments (star) and Zuckerkandl and Hirschfeld canals (arrow). (c) Interradicular fibers and interradicular bone (I) (Mag. X 200). 


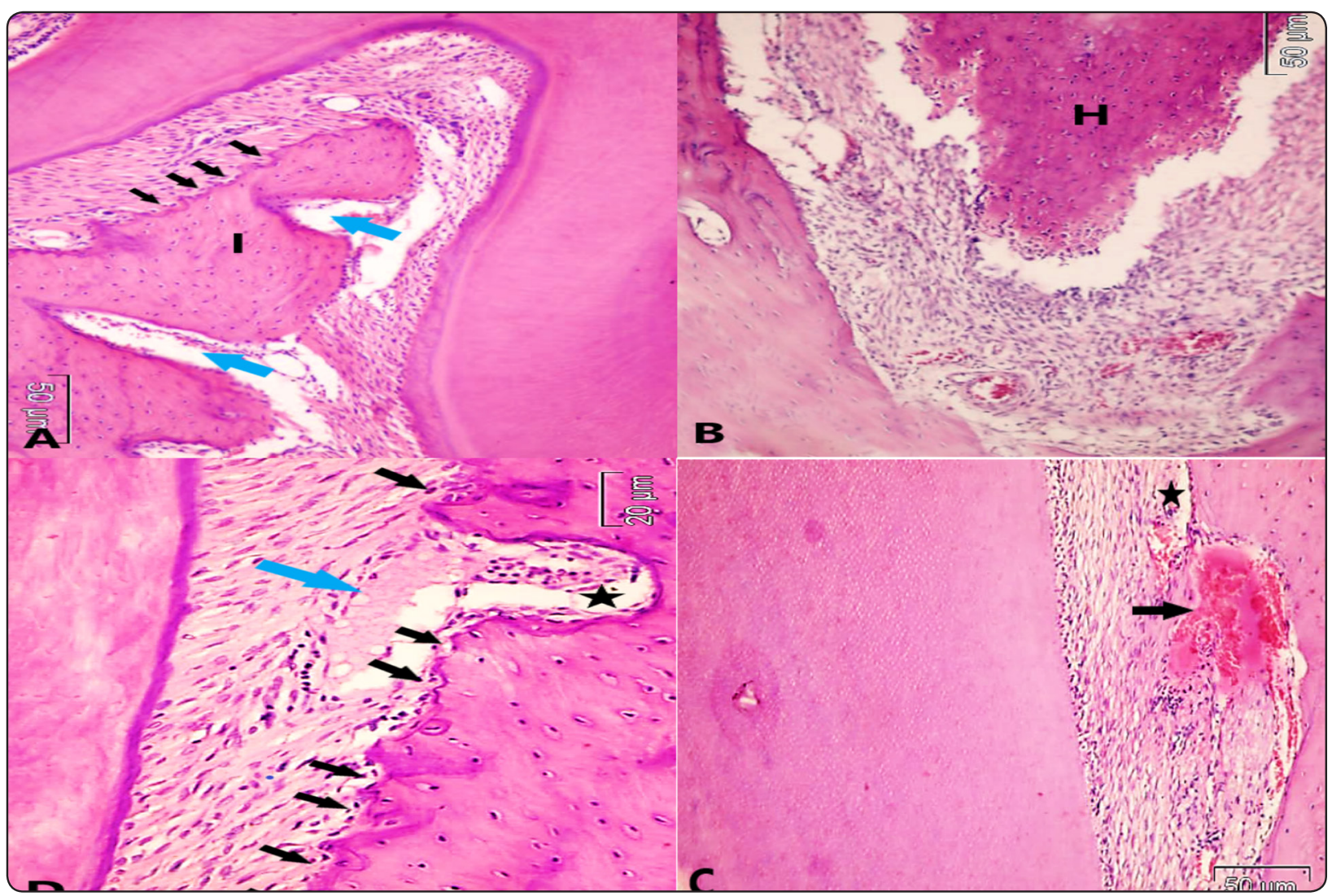

Fig. (2) A photomicrograph of group II showing (A) dissociation and areas of destruction of periodontal ligaments in interradicular area, widening of Zuckerkandl and Hirschfeld canals (blue arrows). Howship's lacunae in the interradicular bone surface (I) surface (black arrows). (B) dissociation and detachment of apical fibers from tooth side with dilated blood vessel engorged with RBCs and inflammatory cell infiltration with dilated blood vessel engorged with RBCs. Notice the hypercementosis in the apical cementum. (C) detachement of oblique fibers from bone side (star) large hemorrhage area (arrow). (D) widening of Zuckerkandl and Hirschfeld canals (star), oblique fibers with focal area of dissolved fiber (blue arrow), Howship's lacunae and osteoclasts on the bone surface (black arrows). (Mag. X 200,400)

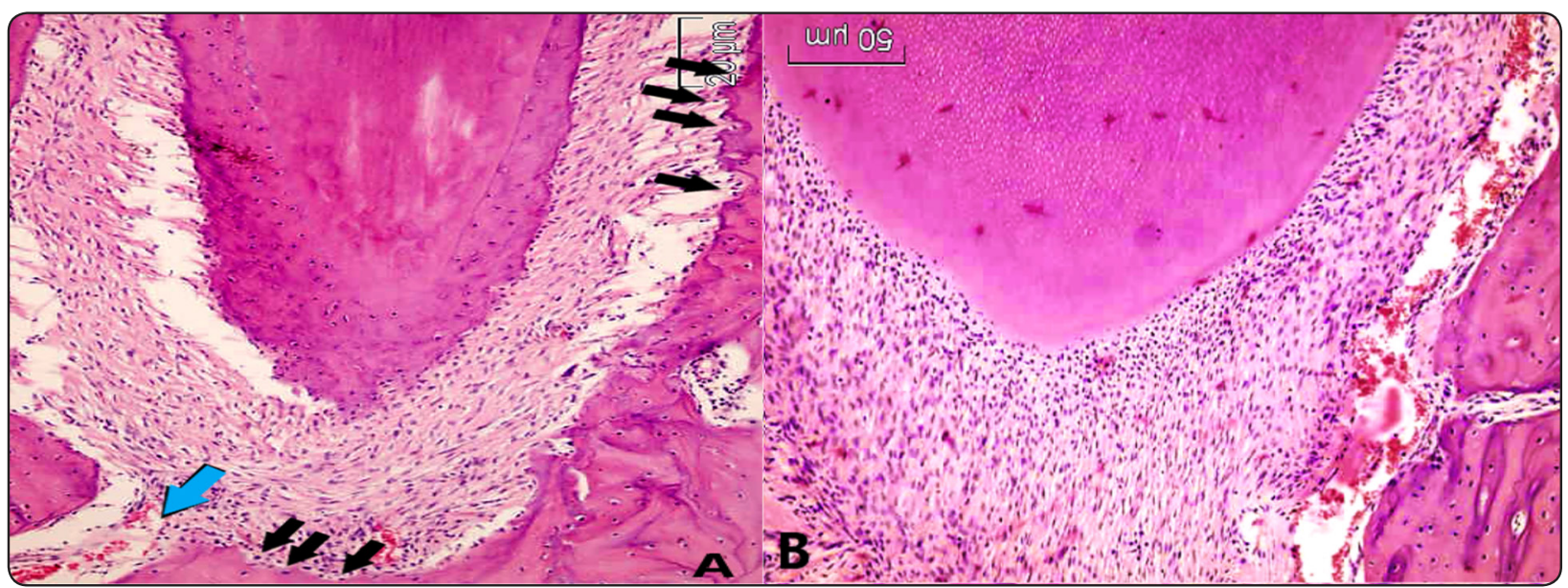




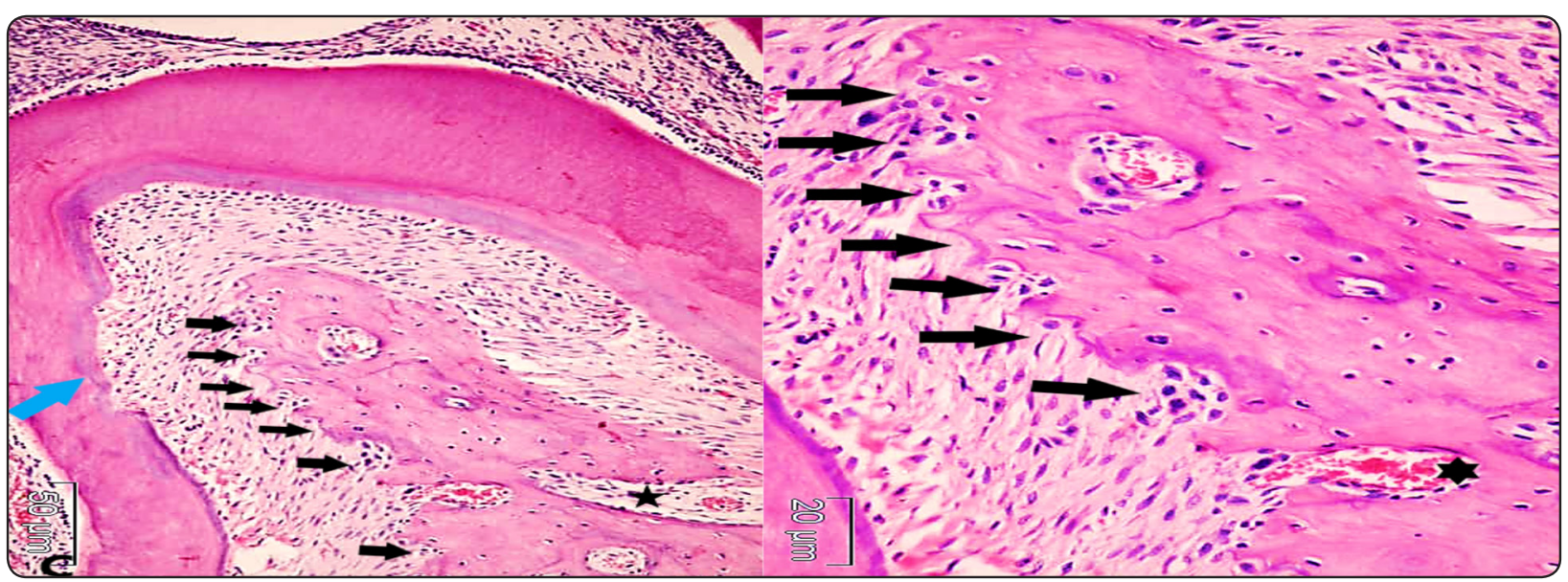

Fig. (3) A photomicrograph of group III showing (A) dissociation and detachment of apical periodontal ligaments from both bone and root surface, widening of Zuckerkandl and Hirschfeld canals (blue arrow). Howship's lacunae in the interradicular bone surface (black arrows). Notice the hypercementosis in the apical cementum. (B) apical periodontal ligaments with the infiltration of inflammatory cell and the dilated blood vessel that is engorged with RBCs and the infiltration of inflammatory cell with dilated blood vessel that is engorged with RBCs. C) focal detachment of interradicular fibers from bone side Howship's lacunae in the bone surface (black arrows) and widening of Zuckerkandl and Hirschfeld canals (star). Focal area of Cementum resorption (blue arrow) (D) higher magnification of (C) photomicrograph showing Howship's lacunae and osteoclasts on the bone surface (black arrows) and widening of Zuckerkandl and Hirschfeld canals (star). . (Mag. X 200,400)
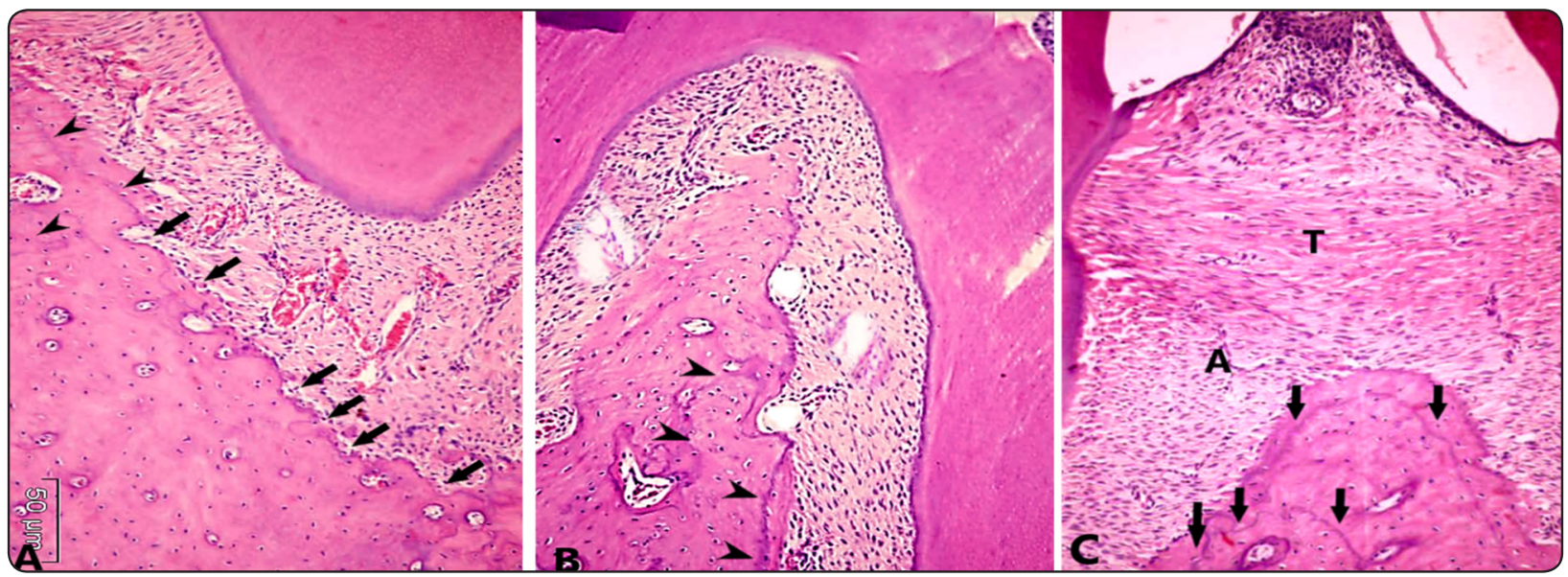

Fig. (4). A photomicrograph of group VI showing (A) almost normal apical periodontal ligaments with dilated blood vessel engorged with RBCs and inflammatory cell infiltration, Howship's lacunae in the interradicular bone surface (black arrows). (B) interradicular PL. with focal areas of fiber dissociation. Reversal lines (arrows heads). (C) almost normal Transeptal (T) and alveolar crest (A) PL fibers. Reversal lines (arrows). (Mag. X 200) 


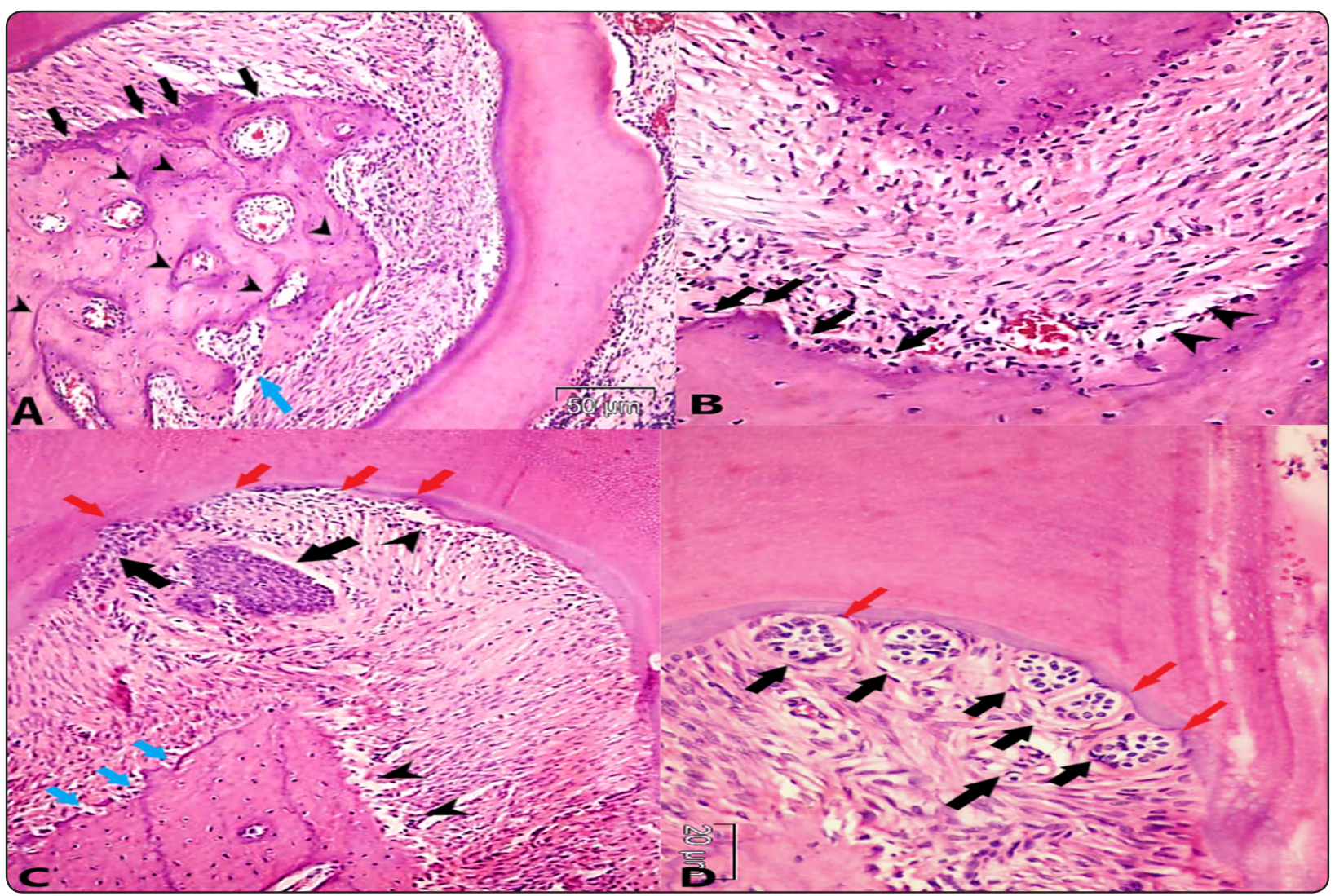

Fig. (5) A photomicrograph of group V showing (A) interradicular PL. with focal area of fiber dissociation, widening of Zuckerkandl and Hirschfeld canals (blue arrow). Howship's lacunae in the interradicular bone surface (black arrows). Reversal lines (arrows heads) Inflammatory cell infiltration. (B) apical periodontal ligaments with detachment areas from bone side (arrow heads), dilated blood vessels engorged with RBCs and inflammatory cell infiltration. Howships lacunae in the bone surface (blue arrows) .(C) Focal detachment of interradicular fibers from both root and bone side Howship's lacunae in the bone surface. Proliferated epithelial rest of Malassezes (black arrows) (D) clusters of epithelial rests of Malassezes in interraddicular area (black arrows), focal areas of cementum resorption (red arrows) . (Mag. X 200,400)

\section{Masson's Trichrome Results}

The histological examination of Masson's trichrome staining to evaluate periodontal ligament and bone regeneration, the negative control samples showed no new bone and periodontal ligament fiber formation, most of fiber were blue colors (mature) minimal amount of new cementum formation. The periodontal ligaments and alveolar bone of rats treated with both STZ revealed mature dissociated fiber (pale blue color) with a few amount of new fibers formation, no new alveolar bone formation and new cementum formation. GSE group of dose $50 \mathrm{mg} / \mathrm{kg}$ showed little amount of fibers formation and focal areas of bone formation. In a group treated with GSE in $100 \mathrm{gm} / \mathrm{kg}$ dose new fiber of periodontal ligaments (strong red colored fibers) also new alveolar bone and new cementum formation (Red color). Group V treated with Gliclazide in $10 \mathrm{mg} /$ $\mathrm{kg}$ revealed a few amount of new fibers, bone and cementum formation. (Fig 6)

\section{Immunohistochemical localization of Bcl2 Results}

Group I (Negative control) showed mild staining reactivity for both periodontal ligaments and alveolar bone to Bcl 2 while Group II (Diabetic group) and group III showed strong staining for both periodontal ligaments and bone to Bcl2. Group IV showed moderate to mild staining reactivity to $\mathrm{Bcl} 2$ for both periodontal ligaments and bone. Group V showed moderate reactivity to bcl2 for periodontal ligaments and bone. (Fig. 7) 


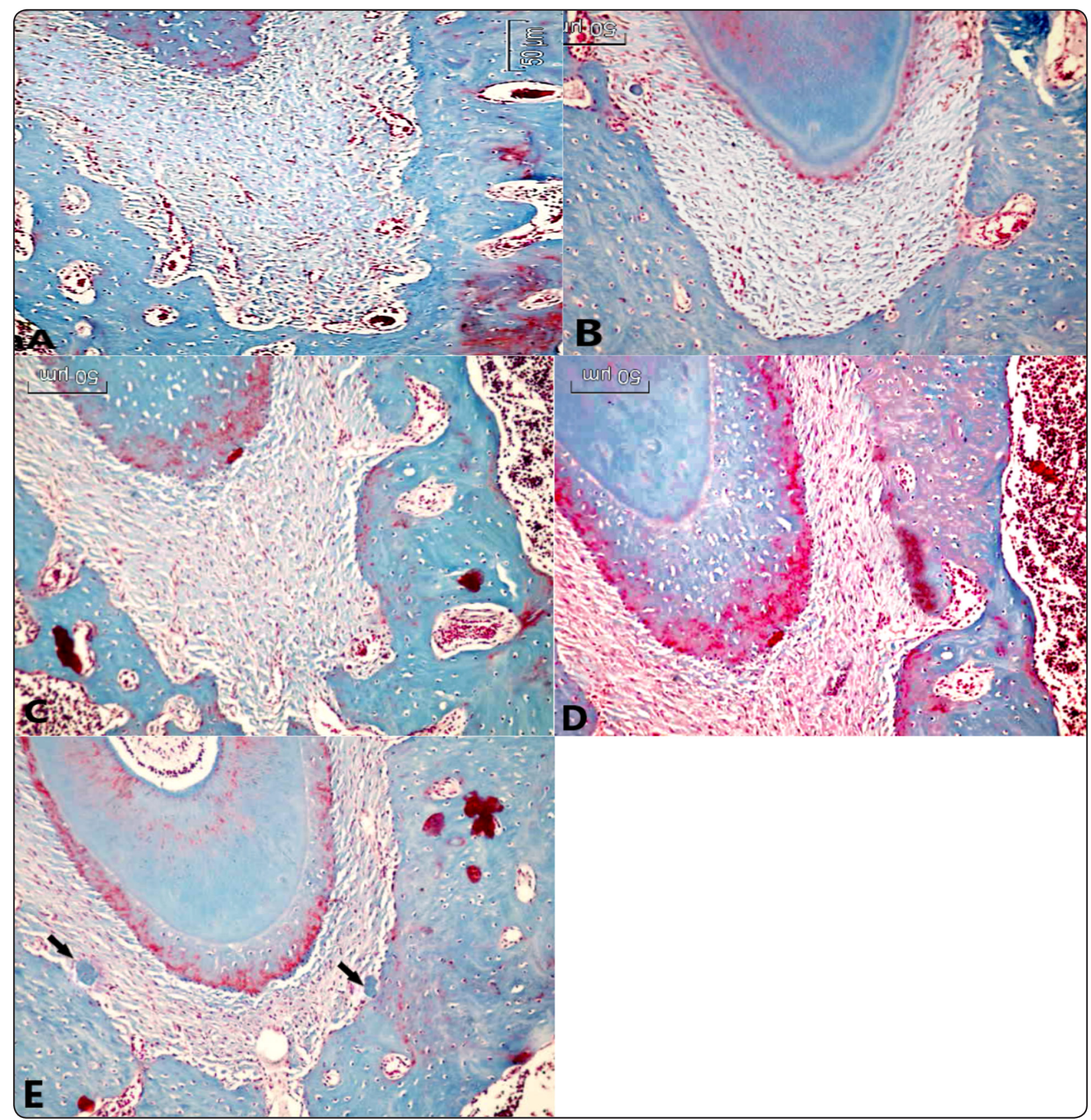

Fig. (6) Photomicrograph of Masson's Trichrome (A) control (-Ve control) no PDL,bone and minimal new cementum formation (Red color). (B) STZ group with minimal new fiber formation, minimal new bone and new cementum. (C) group III showed mostly pale blue colored dissociated fibers, minimal amount of new fibers, new bone formation. (D) Group IV showed new fibers formation (Strong red colors) areas of new bone formation and new cementum. (E) Gliclazide group showed minimal new fibers and little focal areas of new bone formation and new cementum notice the epithelial rest of Malassezes (arrows) 


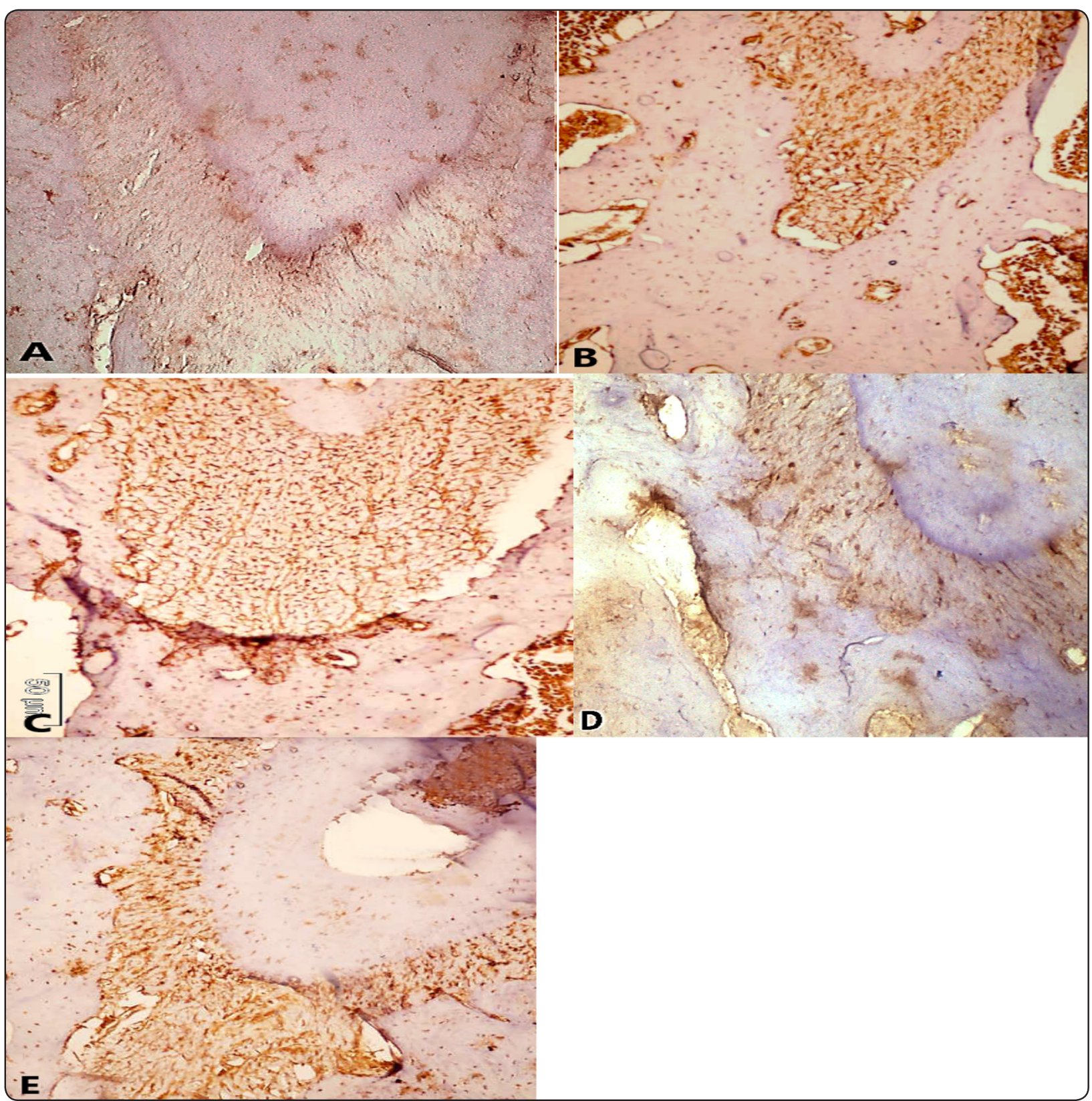

Fig. (7) A photomicrograph of the periodontal ligament and bone incubated with mouse monoclonal antibody of Bcl2 from (A) from Control groups (negative control) showing mild immunostaining reactivity of the periodontal ligaments and bone cells to Bcl2 (B) Group II (Diabetic group) showing severe immunostaining reactivity of the periodontal ligaments and bone cells to $\mathrm{Bcl} 2$ (C) Group III showing severe immunostaining reactivity of the periodontal ligaments and bone cells to $\mathrm{Bcl} 2$ (D) Group IV showing mild to moderate immunostaining reactivity of the periodontal ligaments and bone cells to Bcl2. Group V showed moderate immunostaining reactivity of the periodontal ligaments and bone cells to Bcl2 (Mag. X 250).

\section{Statistical analysis:}

Using SPSS version 22 (SPSS Inc., Chicago,

IL, USA), the statistical analysis of results was performed. ANOVA ( $F$ test) was utilized for analyzing data. After one a way ANOVA (F test), a Post hoc test was carried out to identify whether the individual groups are significantly different. 
Concerning Bcl, the results in table (1) revealed that there is a significant difference among groups for P.L and alveolar bone at $\mathrm{P}$-value $(\mathrm{P}<0.05)$. The diabetic group gave the highest value followed by group III for P.L and alveolar bone. Group V also showed a significant difference with the negative control but with a lesser value than group II and III. Group VI revealed no significance with negative control of value 97.5 and 93.57 for periodontal ligaments and alveolar bone respectively. (Table1, Fig 8)

TABLE (1). Descriptive statistics and results of one way ANOVA test for comparison between means of positive cells in the five groups

\begin{tabular}{ccc}
\hline & P.L & Alveolar bone \\
\hline Group I & $73.94 \pm 3.42^{\mathrm{d}}$ & $75.61 \pm 8.99^{\mathrm{d}}$ \\
\hline Group II & $107.92 \pm 2.04^{\mathrm{a}}$ & $106.37 \pm 2.89^{\mathrm{a}}$ \\
\hline Group III & $101.85 \pm 2.25^{\mathrm{b}}$ & $100.89 \pm 2.24^{\mathrm{b}}$ \\
\hline Group IV & $76.49 \pm 6.46^{\mathrm{d}}$ & $77.78 \pm 4.86^{\mathrm{d}}$ \\
\hline Group V & $97.29 \pm 5.09^{\mathrm{c}}$ & $93.57 \pm 2.32^{\mathrm{c}}$ \\
\hline F test & 119.83 & 68.71 \\
\hline P value $<0.05$ & $<0.001^{* *}$ & $<0.001^{* *}$ \\
\hline
\end{tabular}

**;a,b,c:means significant difference between groups at same column using $F$-Test

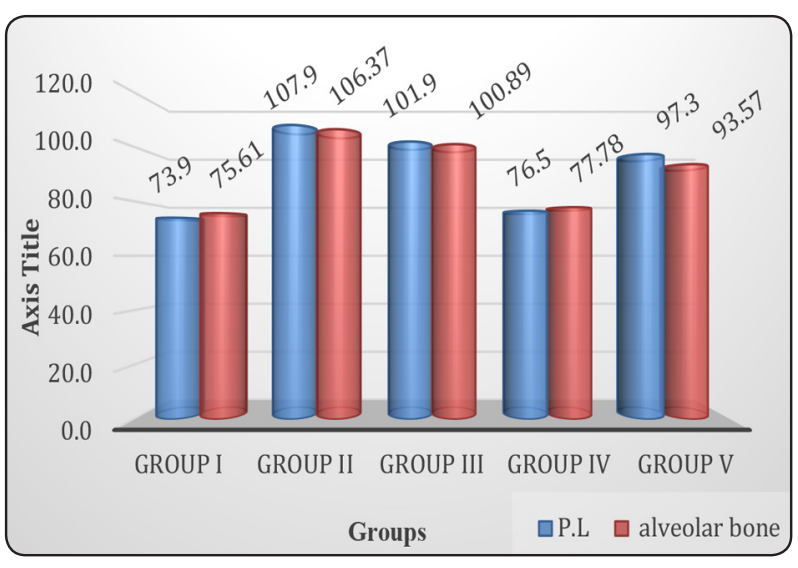

Fig. (8) A double- bar graph represents difference in the mean Bcl2 optical density between different group for periodontal ligaments and alveolar bone.

\section{DISCUSSION}

It is estimated that more than 400 million adults diabetes on a worldwide basis, ${ }^{(30)}$ most of them (>90\%) have type-2 diabetes mellitus that is resulting from combining insulin resistance and failing to compensate by the increase in the production of insulin. ${ }^{(31)}$ Increased gingival inflammation and Periodontitis are observed in subjects with diabetes mellitus. ${ }^{(32,33)}$ Diabetes has a detrimental influence on bone, resulting in an increase in risks of fracture and osteolytic lesions' formation such as those found in periodontitis. Many diabetic difficulties result from diabetes-enhanced inflammation. ${ }^{(34)}$ In periodontal tissues, diabetes results in the enhancement of inflammation, RANKL expression, the loss of periodontal bone, and osteoclastogenesis. ${ }^{(35)}$ Inducing experimental periodontal disease results in the stimulation of $\mathrm{NF}-\varkappa \mathrm{B}$ activation in the fibroblasts of periodontal ligament, osteoblasts, and osteocytes, which is related to the loss of bone and the reduction of bone coupling, which represent two key factors in periodontitis. ${ }^{(36)}$ Diabetes leads to the reduction of bone-lining cells' numbers, osteoblasts, and the fibroblasts of periodontal ligament, which may lead to limiting bone coupling. ${ }^{(37)}$ In diabetic animals, Osseous coupling can significantly reinforced by a TNF specific inhibitor, which can rescue bone formation and expressing bone-producing factors including FGF-2, TGF $\beta$-1, BMP-2, and BMP-6. ${ }^{(38)}$

Oxidative stress is increased by Diabetes increases, which in turn can result in worse insulin action and secretion, consequently resulting in the acceleration of the progression to overt the disease. ${ }^{(39)}$ Studies argued that oxidative stress markers Nox1, Nox2, Nox4, and p47 increase diabetes model rats. ${ }^{(40)}$ Reactive Oxygen Species' elevation (ROS) might have the most critical role to play in the establishment and progression of periodontitis. ${ }^{(41)}$ The increase in ROS results in generating an impaired formation of bone through the activation of bone resorption and forkhead box transcription factors (FoxO) by decreasing Wnt signaling. ${ }^{(42)}$ 
Kolluru et al., reported that the endothelial dysfunction resulting in defective angiogenesis in diabetes has multiple factors that include the decreased growth factors and cytokines, the increased ROS and AGEs, and altered immune cell responses. ${ }^{(43)}$

The previous studies explained the alveolar bone loss, inflammatory cell infiltration, periodontal ligament dissociation, destruction, and blood vessels dilatation which were noted in diabetic group of the present study. The H\&E results were confirmed by the Masson's trichrome stain examination which revealed pale, blue-stained dissociated fibers, with the absence of new bone formation. New cementum formation was noted might compensate for the bone loss in teeth sockets.

Proanthocyanidins are described as the natural antioxidants and complicated polymers of flavonoids. ${ }^{(44)}$ A higher level of proanthocyanidins is contained in legume seeds, grains, various vegetables, and particularly fruits contain. Recently, several studies have revealed their different pharmacological activities including free radical scavenging, anti-inflammatory activities, and antioxidation. Proanthocyanidins are characterized by having application prospects and possible clinical value as a therapeutic agent for diabetic comorbidities. ${ }^{(45)}$

Oligomeric proanthocyanidins (PACs) are contained in grape seed extract (GSE) (Vitis vinifera L.) and display strong antioxidant activity. It has been proven that PACs are capable of controlling malondialdehyde (MDA) and carboxymethyllysine's higher levels, reducing superoxide dismutase, and reducing the activity glutathione (GSH) in mice suffering from induced diabetes mellitus. ${ }^{(46)}$

A histopathological study, ${ }^{(46)}$ which was carried out in 2018, examined grape seed proanthocyanidin extract. The authors reported that GSPE is characterized by having a polyphenolic structure and having a broad spectrum of biological activity. In addition, they measured the loss of alveolar bone morphometrically by utilizing a stereomicroscope. For purposes of histopathological analyses, they performed vascular endothelial growth factor immunohistochemistry, alizarin red staining and matrix metalloproteinase, and inducible factor hypoxia. In addition they determined the relative total inflammatory cells in tartrate acid-positive osteoclast cells. This animal study revealed that the administration of GSPE in $(100 \mathrm{mg} / \mathrm{kg}, 200 \mathrm{mg} /$ $\mathrm{kg}$ ) can cause a decrease in periodontal inflammation and the loss of alveolar bone through the reduction of levels of alpha matrix metalloproteinase and hypoxia-inducible factor, and the increase in osteoblastic activity in diabetic rats having periodontitis. ${ }^{(46)}$ The previous study come inconsistent with the results of group IV animals treated with grape seeds of $100 \mathrm{mg} / \mathrm{kg}$ in the present investigation.

In the present investigation 2 different concentrations of grape seeds were administrated, in group III, the diabetic animals treated with grape seeds of $50 \mathrm{mg} / \mathrm{kg}$ for 6 weeks showed no noticeable effect on alveolar bone resorption or periodontal ligaments degeneration. These results were confirmed by Masson's trichrome which revealed a minimal amount of new fibers and bone formation. While in group IV, diabetic rats were treated with a concentration of 100/ kg for 6 weeks; there was marked improvement indicated through both histological examinations of H\&E and Masson's Trichrome stain, in the alveolar bone through new bone formation and periodontal ligaments showed less dissociation and detachment with new fibers formation. New cementum also demonstrated with more organized and oriental shape. This current study suggested that the grape-seeds dose in group III may be not sufficient to treat the complication of diabetes in alveolar bone and PL or may be the administrated dose need more time to induce the effect that occurred in group IV. The grape seeds dose of $100 / \mathrm{kg}$ group might decrease the oxidative stress on cells and increase their biological activity to regenerate.

Gliclazide represents an anti-diabetic medication, which is a second-generation sulfonylurea. Insulin is released by Sulfonylureas from pancre- 
atic cells and Sulfonylureas act on insulin-sensitive tissues for the enhancement of glucose uptake. ${ }^{(47)}$ Whereas these agents can directly lead to stimulating insulin secretion by the $\beta$-cell, it has been also shown that Sulfonylureas have anti-inflammatory influences. ${ }^{(48)}$ The stimulation of insulin leads to activating distinct pathways that are involved in metabolic regulation such as the phosphatidylinositol-3-kinase (PI3K) cascade. Further, Gliclazide can directly influences PI3K insulin-resistant skeletal muscle for enhancing insulin signalling. ${ }^{(49)}$ The pathway of PI3K signaling has an effect on the inflammatory process, which contributes to increasing neutrophil survival, ${ }^{(50)}$ and the osteoclast differentiation pattern. ${ }^{(51)}$ In tissue from patients with periodontitis, the expression of $\mathrm{PI} 3 \mathrm{~K}$ is higher than that in healthy gingival tissue. ${ }^{(52)}$

In the present investigation, group $\mathrm{V}$ treated with gliclazide $10 \mathrm{mg} / \mathrm{kg}$ for 6 weeks showed infiltration of inflammatory cells, the periodontal ligament has no noticeable improvement in their association and attachments comparing to the diabetic group, unless the orientation of the PL were better than diabetic group. Resorption of alveolar bone and a lot of Howship`s lacunae on the bone surface, numbers of reversal line revealed less new bone formation, the H\&E results were confirmed by results of Masson's trichrome stains as minimal new fibers and bone. Xing et al provided an explanation of these group $\mathrm{V}$ results from the current examination, where they indicated that the higher doses of gliclazides (for example $10 \mathrm{mg} / \mathrm{kg}$ ) can lead to activating the pathway of PI3K/AKT and increasing periodontal bone loss. In addition, they argued that some cytokines could also lead to activating the PI3K/ AKT pathway, resulting in osteoclastogenesis. ${ }^{(53)}$

Clusters and proliferation of epithelial rests of Malassezes were marked and repeated results in the samples of group $\mathrm{V}$ animals as they noticed concentrated in interradicular areas and apical region. Epithelial cell rests' proliferation is frequently found in inflamed periapical lesions. The proliferation of epithelial cells rests takes place in three dimensions, resulting in forming strands or islands of epitheli- um. In turn, these strands of islands of epithelium are invaded by vascular fibrous connective tissue with various degrees of inflammatory infiltrates. ${ }^{(54)}$ During periapical inflammation, several inflammatory mediators, growth factors, and proinflammatory cytokines are released by host cells in the periapical tissues through the innate and adaptive immune responses. ${ }^{(55)}$ Brunette ${ }^{(56)}$ revealed that when the intracellular level of cyclic adenosine monophosphate (cAMP) is elevated by prostaglandins (PGE2), it leads to stimulating epithelial cell rests' growth. In the $10 \mathrm{mg} / \mathrm{kg}$ gliclazide group, there was an increase in the inflammatory cytokine IL-1. It was revealed that IL-1 stimulates osteoclastogenesis through two paralleled events: enhancing RANKL expression directly and suppressing OPG expression. ${ }^{(53)}$ At low concentrations, IL-1 had a proliferative influence on the epithelial cells, which could play a role in the evocation of an inflammatory reaction and the stimulation of Malassez's epithelial cell rests in order to proliferate to form radicular cyst. ${ }^{(57)}$ Accordingly, the present investigation suggested that administration of gliclazide in a dose of $10 \mathrm{mg} / \mathrm{kg}$ could increase the release of some cytokines, particularly IL-1 that stimulate the proliferation of epithelial rest of Malassezes, Thus, the present study recommended that dental care and follow up of the patient treated with gliclazide of $10 \mathrm{mg} / \mathrm{kg}$ to detect any pathosis could be developed due to activation of epithelial rest of Malassezes. The present study suggested that gliclazide of $10 \mathrm{mg} / \mathrm{kg}$ could mediate an inflammatory process which causes resorption in the bone surfaces and cementum on the tooth surface.

The histological results were indicated through immunohistochemical analysis of $\mathrm{Bcl} 2$. Concerning $\mathrm{Bcl} 2$, the results showed a significant difference between groups for PDL and alveolar bone at $\mathrm{P}$-value $(\mathrm{P} \leq 0.05)$. The diabetic group and Grape seeds of $50 \mathrm{mg} / \mathrm{kg}$ gave the highest value followed by gliclazide group for P.L and alveolar bone comparing to negative control group. The grape seeds group of $100 \mathrm{mg} / \mathrm{kg}$ showed no significant difference with the untreated control group. 
Apoptosis, which is also known as the programmed death of cell, represents a form of physiological cell death. When there is infection, inflammation or tissue remodeling, it increases or decreases. ${ }^{(58)}$ Apoptosis is considered a very important process that has an effect on the normal development and tissue homeostasis. Apoptotic proteins such as bcl-2 and Bax proteins can contribute to regulating the apoptosis. In addition, the Bcl-2 is utilized as anti-apoptotic protein, whereas the Bax is utilized as a proapoptotic protein, and the balance between such proteins helps to determine the apoptotic process. ${ }^{(59)}$

The Bcl-2 family members has an integral role to play in apoptosis. Nevertheless, they can also contribute to several other cellular functions. Among all the Bcl-2 family members, Isoforms are recognized and some of them are well described. The therapeutics which target BCL-2 indicates a great promise of treating cancer and degenerative diseases. ${ }^{(60)}$

There is a well-recognized fact that prolonged hyperglycemia can cause the dysfunction of several organ systems. Furthermore, type $2 \mathrm{DM}$ is related to the difficulties in the kidneys, eyes, and arteries, and impairing these organ systems is involved in inflammatory processes. Many studies revealed the overexpression of $\mathrm{Bcl}-2$ and $\mathrm{Bax}$ proteins in various tissues with hyperglycemia. ${ }^{(61)}$

On the other hand, former studies have argued that apoptosis is involved in inflammatory periodontal disease' pathogenesis. ${ }^{(58)}$ They also revealed that the higher frequency of Bcl-2 expression leads to progressive periodontal destruction. ${ }^{(62)}$

To the best of our knowledge, this current study is one of few trials to demonstrate the effect of GSE on the expression of $\mathrm{Bcl} 2$ in the alveolar bone and periodontal ligament in diabetic conditions.

A study of Güçlü et al indicated that using grape seed as treatment might be useful against apoptosis and oxidative stress in diabetic rats. ${ }^{(63)}$ The exposure to GSEs resulted in the activation of cleavage of caspase-2, caspase-3 and caspase-9 in HCT-116 cells, the induction of p53-mediated mitochondrial apoptosis signaling pathway with a concentrationdependent decrease in the level of expression of the survival protein Bcl-2, and the increase in the level of expression of the pro-apoptotic proteins, Bax and Bak. ${ }^{\left({ }^{64}\right)}$ The previous study comes inconsistent with the investigation results of group seeds of dose $100 \mathrm{mg} / \mathrm{kg}$ as there was no significant difference with negative control. While in group III grape seeds of dose $50 \mathrm{mg} / \mathrm{kg}$ the bcl2 expression was high as mentioned, this indicates the suggestion of insufficient dose of grape seeds or insufficient time of treatment.

In group $\mathrm{V}$ the bcl2 expression showed significant difference from untreated controls this comes in the agreement with a study of Kanazawa et al, the authors revealed animals that are treated with gliclazide at a $10 \mathrm{mg} / \mathrm{kg}$ dose, suggesting a hypoglycemic impact at this dose and an increase in the loss of bone in periodontal disease. Another study indicated that metformin has significantly resulted in the activation of AMPK in dose- and time-dependent manners, and the induction of endothelial nitric oxide synthase (eNOS) and bone morphogenetic protein-2 (BMP-2) expressions, ${ }^{(65)}$ that may suggest the persistence of the inflammatory process and cell apoptosis and in turn explain the high bcl2 expression in group $\mathrm{V}$.

According to the present study, blood glucose evaluation at the beginning and end of the expirement is recommend in further researches to investigate whether GSE has a hypoglycemic effect or not in diabetic condition

\section{CONCLUSION}

Grape seeds of $100 \mathrm{mg} / \mathrm{kg}$ improve the condition of periodontal ligaments and alveolar bone of diabetic animals and could represent a supplemental medication for treatment the dental complication of diabetes mellitus. It is required to carry out further comprehensive clinical and experimental studies for investigating the beneficial influences of grape seed extracts in diabetes mellitus, which indicate decrease in $\mathrm{Bcl} 2$ expression. 


\section{REFERENCES}

1. Ying-Ying Wu, E Xiao, and Dana Graves. Diabetes mellitus related bone metabolism and periodontal disease. Inter J of Oral Sci. 2015;7(2):63-72.

2. Neves L, Esquisatto M, Santos G, Amaral M, Mendonca F. Effects of microcurrent application and $670 \mathrm{~nm} \mathrm{In-}$ GaP low-level laser irradiation on experimental wound healing in healthy and diabetic Wistar rats. Laser Phys. 2013;23(3):035604.

3. Polak D, and Shapira L. An update on the evidence for pathogenic mechanisms that may link periodontitis and diabetes. J of Clin Periodont 2018;45(2):150-166.

4. Nurullina G, and Akhmadullina G. Features of bone metabolism in diabetes. Endo J 2017; 20 (3): 82-89.

5. Sundararaghavan V, Mazur M, Evans B, Liu J and Ebraheim N. Diabetes and bone health: latest evidence and clinical implications. Ther Adv Musculoskelet 2017;9(3):6774.

6. Jaradat N, Qadoumi M, Qadoumi AN. Regular swimming exercise improves metabolic syndrome risk factors: a quasiexperimental study. BMC Sports Sci Med Rehabil 2021;13(22):1-7.

7. Mealey B, and Ocampo G. Diabetes mellitus and periodontal disease. Periodontol 2000 2007; 44:127-153

8. Srivastava S, Singh D, Patel S, and Singh M. Role of enzymatic free radical scavengers in management of oxidative stress and autoimmune disorders. Inter J of Bio Macromol 2017; 101:502-517.

9. Nassar H, Kantarci A, van Dyke TE. Diabetic periodontitis: a model for activated innate immunity and impaired resolution of inflammation. Periodont 2000 2007; 43:233.

10. Özcan E, Saygun N, Rahşan I, Yıldırım K, Uğur M., and Sait Y. Increased visfatin expression is associated with nuclear factor-kappa B and phosphatidylinositol 3-kinase in periodontal inflammation. Clin Oral Inves 2017; 21:1113-1121.

11. Kholsa S. minireview. The OPG/RANKL/RANK system. Endocrin 2001; 142(12): 5050-5055.

12. Yi H, Stephen J, Fei Ch, and Shazib P. The anti-oxidant and pro-oxidant dichotomy of Bcl-2. J of Bio Chem 2016; 397(7): 585-593.

13. Anuj R, Piyush J, Ela C, and Vivian G. Remodeling of mitochondrial morphology and function: an emerging hallmark of cellular reprogramming Cell. The Inter J on the Bio of Stress 2019; 3(6):181-194.

14. Um HD. Bcl-2 family proteins as regulators of cancer cell invasion and metastasis: a review focusing on mitochondrial respiration and reactive oxygen species. Oncotarget $\mathrm{j}$ 2016;7:5193-5203.

15. Witters LA. The blooming of the French lilac. $\mathrm{J}$ of the clin inves 2001; 108:1105-07.

16. Madhavi G, Sanjay D, Daphisha M, Paulami P, Subhabrata $\mathrm{R}$, and Bhaskar M. Grape seed extract: having a potential health benefits. J of Food Sci and Tech 2020; 57:12051215 .

17. Anshu MR, Manjeshwar SB, Craig AE, and Santosh KK. Grape Seed Proanthocyanidins Induce Apoptosis through p53, Bax, and Caspase 3 Pathways. Neoplasia 2005;7 (1):24-36.

18. Bharat K. A review on potential properties and therapeutic applications of grape seed extract. World J of Pharmaceut Res 2020; 9 (5): 2519-2540.

19. Cho ML, Heo YJ, and Park MK. Grape seed proanthocyanidin extract (GSPE) attenuates collagen-induced arthritis. Immuno Letters 2009; 124:102-110.

20. Woo YJ, Joo YB, and Jung YO. Grape seed proanthocyanidin extract ameliorates monosodium iodoacetate-induced osteoarthritis. Exper molecul medi 2011; 43:561-570.

21. Toker H, Balci YA, Lektemur AF, and Gevrek M. Morphometric and histopathological evaluation of the effect of grape seed proanthocyanidin on alveolar bone loss in experimental diabetes and periodontitis. J of Periodl Res 2018; 53:478-486.

22. Park JS, Park MK, Oh HJ, Woo YJ, Lim MA, Lee JH, Ju JH, Jung YO, Lee ZH, Park SH, Kim HY, Cho ML, and Min JK. Grape-seed proanthocyanidin extract as suppressors of bone destruction in inflammatory autoimmune arthritis. PLoS One. 2012;7(12):e51377.

23. Ahmad SF, Zoheir KM, Abdel-Hamied HE, Attia SM, Bakheet SA, Ashour AE, Abd-Allah AR. Grape seed proanthocyanidin extract protects against carrageenaninduced lung inflammation in mice through reduction of pro-inflammatory markers and chemokine expressions. Inflamm. $2014 ; 37(2): 500-511$.

24. La VD, Bergeron C, Gafner S, and Grenier D. Grape seed extract suppresses lipopolysaccharide-induced matrix metalloproteinase (MMP) secretion by macrophages and 
inhibits human MMP-1 and -9 activities. J Periodontol. 2009;80:1875-1882

25. Furiga A, Lonvaud-Funel A, and Badet C. In vitro study of antioxidant capacity and antibacterial activity on oral anaerobes of a grape seed extract. Food Chem. 2009;113:1037-1040.

26. Faul F, Erdfelder E, Lang, A, and Buchner A. G Power 3: A flexible statistical power analysis program for the social, behavioral, and biomedical sciences. Behavior Res Method 2007; 39: 175-191.

27. Balci YH, Toker H, and Goze F. The histopathological and morphometric investigation of the effects of systemically administered boric acid on alveolar bone loss in ligatureinduced periodontitis in diabetic rats. Acta Odontologica Scandinavica 2014; 72:729-736.

28. Abir TE, Amany AE, and Ahmed AJ. Protective effect of red grape seeds proanthocyanidins against induction of diabetes by alloxan in rats. J of Pharmaco Res 2005; 52: 264-270.

29. Sena CM, louro T, Matafome P, Nunes P, and Monteiro R. Antioxidant and vascular effects of gliclazide in type 2 diabetic rats fed high-fat diet. J of Physiolical Res 2009; 58: 203-209.

30. IDF Diabetes Atlas. 8th ed. Brussels, Belgium: International Diabetes Federation; 2017.

31. Sami W, Ansari T, Butt NS, Hamid MRA. Effect of diet on type 2 diabetes mellitus: a review. Int J Health Sci (Qassim). 2017;11(2): 65-71.

32. Novotna M,Podzimek S, Broukal Z, Lencova E, Duskova J. Periodontal diseases and dental caries in children with type 1 diabetes mellitus. Mediat Inflamm. 2015;2015:379626

33. Patil VS, Patil VP, Gokhale N, Acharya A, Kangokar P. Chronic periodontitis in type 2 diabetes mellitus: oxidative stress as a common factor in periodontal tissue injury. $\mathrm{J}$ Clin Diagn Res. 2016;10(4):Bc12-6

34. Zhen Huang 1,2 \& Xiyan Pei3,2 \& Dana T. Graves2. The Interrelationship Between Diabetes, IL-17 and Bone Loss. Current Osteoporosis Reports (2020) 18:23-31

35. Graves DT, Corrêa JD, Silva TA. The Oral Microbiota Is Modified by Systemic Diseases. J Dent Res. 2019;98: 148-156

36. Zheng J, Chen S, Albiero ML, Vieira GHA, Wang J, Feng JQ, and Graves DT. Diabetes Activates Periodontal Liga- ment Fibroblasts via NF- $\varkappa$ B In Vivo. J Dent Res 2018; 97(5):580-588

37. Weinberg E, Maymon T, Moses O, Weinreb M. Streptozotocininduced diabetes in rats diminishes the size of the osteoprogenitor pool in bone marrow. Diabetes Res Clin Pract 2014;103(1):35- 41.

38. Pacios S, Kang J, Galicia J, Gluck K, Patel H, OvaydiMandel A, Petrov S, Alawi F, and Graves DT. Diabetes aggravates periodontitis by limiting repair through enhanced inflammation. FASEB J $2012 ; 26(4): 1423-1430$.

39. Mizutani K, Park K, Mima A, Katagiri S, and King GL. Obesity-associated gingival vascular inflammation and insulin resistance. J Dent Res 2014, 93, 596-601.

40. Kido D, Mizutani K, Takeda K, Mikami R, Matsuura $\mathrm{T}$, Iwasaki K, and Izumi Y. Impact of diabetes on gingival wound healing via oxidative stress. PLoS ONE 2017;12:e189601.

41. Sczepanik FSC, Grossi ML, Casati M, Goldberg M, Glogauer M, Fine N, and Tenenbaum HC. Periodontitis is an inflammatory disease of oxidative stress: We should treat it that way. Periodontol. 2000 2020;84:45-68.

42. Galli C, Passeri G, and Macaluso GM. FoxOs, Wnts and oxidative stress-induced bone loss: New players in the periodontitis arena? J Perio Res 2011;46:397-406.

43. Kolluru GK, Bir SC, and Kevil CG. Endothelial Dysfunction and Diabetes: Effects on Angiogenesis, Vascular Remodeling, and Wound Healing. Int J Vasc Med. 2011;46(4):397-406.

44. Smeriglio A, Barreca D, Bellocco E, Trombetta D. Proanthocyanidins and hydrolysable tannins: occurrence, dietary intake and pharmacological effects. Br J Pharmacol. 2017;174(11):1244-1262.

45. Chen F, Wang H, Zhao J, Yan J, Meng H, Zhan H, Chen L, Yuan L. Grape seed proanthocyanidin inhibits monocrotaline-induced pulmonary arterial hypertension via attenuating inflammation: in vivo and in vitro studies. J Nutr Biochem. 2019 May;67:72-77.

46. Al-Malki AL, Sayed AAR, and El Rabey HA. Proanthocyanidin Attenuation of Oxidative Stress and NF-kappa B Protects Apolipoprotein E-Deficient Mice against Diabetic Nephropathy. Evid-Based Complement Altern Med. 2013:1-8.

47. Toker H, Yuce H.B, Alpan AL, Gevrek F, and Elmastas M. Morphometric and histopathological evaluation of the ef- 
fect of grape seed proanthocyanidin on alveolar bone loss in experimental diabetes and periodontitis. J. Perio Res. 2018;53:478-486.

48. Kumar N, and Dey CS. Gliclazide increases insulin receptor tyrosine phosphorylation but not p38 phosphorylation in insulin-resistant skeletal muscle cells. J Exp Biol. 2002;205(23):3739-3746.

49. Rakel A, Renier G, Roussin A, Buithieu J, Mamputu JC, and Serri O. Beneficial effects of gliclazide modified release compared with glibenclamide on endothelial activation and low-grade inflammation in patients with type 2 diabetes. Diabetes Obes Metab. 2007;9(1):127-9.

50. Sarkar A, Hellberg L, Bhattacharyya A, Behnen M, Wang K, Lord JM, Möller S, Kohler M, Solbach W, and Laskay T. Infection with Anaplasma phagocytophilum activates the phosphatidylinositol 3-Kinase/Akt and NF- $x$ B survival pathways in neutrophil granulocytes. Infect Immun. 2012 ;80(4):1615-1623.

51. Madeira MF, Queiroz-Junior CM, Costa GM, Santos PC, Silveira EM, Garlet GP, Cisalpino PS, Teixeira MM, Silva TA, and Souza Dda G. MIF induces osteoclast differentiation and contributes to progression of periodontal disease in mice. Microbes Infect. 2012;14(2):198-206.

52. Özcan E, Saygun NI, Ilıkçı R, Karslığlu Y, Muşabak U, and Yeşillik S. Increased visfatin expression is associated with nuclear factor-kappa B and phosphatidylinositol 3-kinase in periodontal inflammation. Clin Oral Investig. 2017;21(4):1113-1121.

53. Xing R, Zhang Y, Li C, Sun L, Yang L, Zhao J, and Liu X. Interleukin-21 promotes osteoclastogenesis in RAW264.7 cells through the PI3K/AKT signaling pathway independently of RANKL. Int J Mol Med. 2016 ;38(4):1125-1134.

54. Seltzer S, Soltanoff W, and Bender IB. Epithelial proliferation in periapical lesions. Oral Surg Oral Med Oral Pathol. 1969;27(1):111-121.

55. Matsumoto A, Anan H, and Maeda K. An immunohistochemical study of the behavior of cells expressing interleukin-1 and interleukin-1 within experimentally induced periapical lesions in rats. J Endod 1998;24:811-816
56. Brunette DM. Cholera toxin and dibutyl cyclic-AMP stimulate the growth of epithelial cells derived from epithelial cell rests from porcine periodontal ligament. Arch Oral Biol 1984;29:303-309.

57. Qureshi Wu, Asif M, Qari IH, and Qazi JA. Role of interleukin-1 in pathogenesis of radicular cyst. J Ayub Med Coll Abbottabad. 2010;22(2):86-7.

58. Li CH, and Amar S. Inhibition of SFRP1 reduces severity of periodontitis. J Dent Res. 2007 Sep;86(9):873-877.

59. Gokalp-Ozkorkmaz E, Kirman G, Pekkolay Z, Asir F, and Deveci E. Expression of Apoptotic Proteins Bax and Bcl-2 in Blood Cells of Type 2 Diabetic Patient. Proceedings 2018;2(25):1563-1570.

60. Chloe FA, Warren, Michelle W, Wong-Brown and Nikola A. Bowden BCL-2 family isoforms in apoptosis and cancer. Cell Death \& Disease. 2019;10: 177-190.

61. Bulut S, Uslu H, Ozdemir BH, and Bulut OE. Expression of caspase-3, p53 and Bcl-2 in generalized aggressive periodontitis. Head Face Med. 2006 20;2:17.

62. Abu-El-Asrar AM, Dralands L, Missotten L, Al-Jadaan IA, and Geboes K. Expression of apoptosis markers in the retinas of human subjects with diabetes. Investig Ophthalmol Vis Sci. 2004;45:2760-2766.

63. Güçlü A, Yonguç N, Dodurga Y, Gündoğdu G, Güçlü Z, Yonguç T, Adıgüzel E, and Turkmen K. The effects of grape seed on apoptosis-related gene expression and oxidative stress in streptozotocin-induced diabetic rats. Ren Fail. 2015;37(2):192-197.

64. Zhang C, Chen W, Zhang X, Zheng Y, Yu F, Liu Y, and Wang Y. Grape seed proanthocyanidins induce mitochondrial pathway-mediated apoptosis in human colorectal carcinoma cells. Oncol Lett. 2017;14(5):5853-5860.

65. Kanazawa I, Yamaguchi T, Yano S, Yamauchi M, and Sugimoto T. Metformin enhances the differentiation and mineralization of osteoblastic MC3T3-E1 cells via AMP kinase activation as well as eNOS and BMP-2 expression. Biochem Biophys Res Commun. 2008;375(3):414-419. 